\title{
Photocatalytic Disinfection of Legionella pneumophila on Silver-Doped Titania Thin Films
}

\author{
Eiko Obuchi $^{1}$, Keisuke Yanagi ${ }^{1}$, Katsumi Katoh ${ }^{1}$, Ataru Kuroiwa ${ }^{2}$, Toshinori Soejima ${ }^{2}$ \& Katsuyuki Nakano ${ }^{1}$ \\ ${ }^{1}$ Department of Chemical Engineering, Fukuoka University, Fukuoka, Japan \\ ${ }^{2}$ Department of Microbiology and Immunology, School of Medicine, Fukuoka University, Fukuoka, Japan \\ Correspondence: Eiko Obuchi, Department of Chemical Engineering, Fukuoka University, 8-19-1 Nanakuma, \\ Jonan-ku, Fukuoka 814-0180, Japan. Tel: 81-92-871-6631. E-mail: eobuchi@fukuoka-u.ac.jp
}

\author{
Received: January 10, 2014 Accepted: February 14, 2014 Online Published: February 27, 2014 \\ doi:10.5539/enrr.v4n2p1 \\ URL: http://dx.doi.org/10.5539/enrr.v4n2p1
}

\begin{abstract}
The activities of thin films of titania and silver-doped titania for the photocatalytic disinfection of Legionella pneumophila in aqueous medium were examined and compared with each other. Both photocatalytic films disinfected L. pneumophila under UV irradiation; the Ag-doped film showed a higher activity than the non-doped one. The silver-doped titania film even showed a slight activity in disinfecting L. pneumophila under the absence of UV irradiation. This bactericidal effect in darkness overcomes a weakness of photocatalytic disinfection. Scanning electron micrographs of L. pneumophila after photocatalytic disinfection showed that the cell walls of the bacteria were destroyed in the presence of the thin film of Ag-doped titania. Furthermore, the photocatalytic action caused decomposition of the endotoxin leaked from the dead bacteria.
\end{abstract}

Keywords: silver, titania, disinfection, Legionella, photocatalysis

\section{Introduction}

Many bacteria that are normally present in our surroundings can cause serious disease in the elderly, the infirm, infants or other persons with compromised immune systems. Legionella pneumophila is well-known bacterium that can cause serious pneumonia (legionnaires' disease). In Japan, these bacteria are occasionally detected in facilities such as hot-spring resorts or cooling towers. In general, water in such facilities is disinfected by treatment with chlorine. However, because L. pneumophila is tolerant to chlorine, it can still cause infection. Therefore, a new method of sterilization using ultraviolet (UV) radiation or ozone is required instead of chlorination. Sterilization in the presence of a photocatalyst is one possible method of sterilization that has attracted some attention.

Titanium dioxide $\left(\mathrm{TiO}_{2}\right.$, titania) is the most widely used photocatalyst; titania is safe enough to add to food, cheap, and stable. When it is subjected to UV irradiation (under $380 \mathrm{~nm}$ ), titania generates hydroxyl radicals that are strong oxidizing agents capable of fully decomposing organic compounds to $\mathrm{CO}_{2}$ and $\mathrm{H}_{2} \mathrm{O}$. In early stage of research using $\mathrm{TiO}_{2}$ photocatalyst, many researchers used $\mathrm{TiO}_{2}$ powders (Augugliaro et al., 1991; Hoffmann, Martin, Choi, \& Bahnemann, 1995). For practical purposes, however, it will be necessary to immobilize the photocatalyst (Chen \& Dionysiou, 2006; R. Nakano, Chand, Obuchi, Katoh, \& K. Nanano, 2011). Furthermore, researches were also expanded which various metals were doped on $\mathrm{TiO}_{2}$ in order to add a new function, such as a visible light response (Chand, Obuchi, Katoh, Luitel, \& Nakano, 2011; Liu, P. Wang, X. Wang, H. Yu, \& J. Yu, 2012).

On the other hand, because bacteria consist of organic compounds such as proteins, it is possible to decompose them by using a suitable photocatalyst (Rincón \& Pulbarin, 2003; Reddy, Venugopal, \& Subramanyam, 2007; Rengifo-Herrera et al., 2008). In the field of bacteria disinfection, metal doped $\mathrm{TiO}_{2}$, such as $\mathrm{Ag}$-doped $\mathrm{TiO}_{2}(\mathrm{~L}$. Liu, Z. Liu, Bai, \& Sun, 2012; Ubonchonlalate, Sikong, \& Saito, 2012) has been studied. As it is said from ancient times that silver has a bactericidal effect, so that $\mathrm{Ag}$-doped $\mathrm{TiO}_{2}$ has attracted having higher activity for disinfection than non-doped $\mathrm{TiO}_{2}$ photocatalyst. In a previous study (Matsuo, Takeshita, \& Nakano, 1990; Obuchi, Yamamoto, \& Nakano, 1995; Obuchi, Hashimura, \& Nakano, 1999), we developed a new method for preparing transparent thin films of titania that showed photocatalytic activity against various organic compounds, such as 2, 4-dinitrophenol, under UV irradiation (Obuchi et al., 1995; Shiraishi, Toyoda, Fukinbara, Obuchi, \& 
Nakano, 1999). We have also tested the ability of these films to inactivate viruses by using Lactobacillus PL-1 phages (Kakita et al., 2000) and the ability of titania thin film coated on glass plates to disinfect L. pneumophila (Hayakawa, Kuroiwa, Higashi, \& Nakano, 2007). In this work, transparent $\mathrm{Ag}-\mathrm{TiO}_{2}$ solution which doped $\mathrm{Ag}$ to the transparent titania developed in the previous report (Obuchi et al., 1995) was prepared. We report on our investigations of the comparative activities of titania and Ag-doped titania thin film coated on glass tube in the photocatalytic disinfection of L. pneumophila in aqueous medium.

\section{Material and Methods}

\subsection{Preparation of the Photocatalysts}

Amorphous titania powder, which prepared by hydrolysis and condensation polymerization of titanium tetra-iso-propoxide (Kishida Chemical Co. Ltd., Osaka), as reported previously (Obuchi et al., 1995), was dissolved in 30\% aqueous hydrogen peroxide (Wako Pure Chemical Industries, Ltd., Tokyo). In the case of the Ag-doped titania, the required quantity of silver acetate (Wako Pure Chemical Industries, Ltd., Tokyo) which consist of $3 \mathrm{wt} \%$ to titania powder was added at the same time, and the mixture was stirred at $293 \mathrm{~K}$ for 2 hours. A transparent yellow gel was formed with the bubble of oxygen generated by decomposition of hydrogen peroxide. The gel was peptized again by adding 30\% hydrogen peroxide aqueous solution and then the yellow transparent solution was stirred until generating of oxygen was completed. Thus, transparent titania or silver doped titania solution were obtained.

The interior of a cleaned quartz glass tube (internal diameter: $10 \mathrm{~mm}$, outside diameter: $12 \mathrm{~mm}$, length: $270 \mathrm{~mm}$ ) was coated with the titania or Ag-doped titania solution. The coated tube was dried at room temperature, then calcined at $773 \mathrm{~K}$ for 2 hours. These operations (coating - drying - calcination) were repeated 10 times. Thus, the glass tube reactors coated with a thin film of titania or Ag-doped titania were obtained. About $300 \mathrm{~nm}$ of thickness of the titania thin films were also prepared using the same titania solution on glass plates calcined at 473-773 K for X-ray diffraction (XRD) analysis. XRD patterns of titania thin film were measured using Mac science M03X-HF (Model No. 1031) with $\mathrm{Cu} \mathrm{K \alpha}$ irradiation $(\lambda=1.54050 \AA)$ in the range of 20-60 (20), operated at $40 \mathrm{kV}$ and $20 \mathrm{~mA}$.

\subsection{Experimental Procedures}

The strain of L. pneumophila (Serogroup1) was donated by Professor Yoshida (Department of Microbiology, Faculty of Medical Science, Kyushu University). This strain was cultured on buffered charcoal yeast extract (BCYE) agar plates (Eiken Chemical Co. Ltd., Tokyo) at 310K for at least seven days. The bacteria were then suspended in sterile water and adjusted to $10^{5} \mathrm{cfu} / \mathrm{mL}$ with sterile water to prepare the test suspension.

Figure 1 is a schematic of the experimental apparatus that we used in this work. A $200 \mathrm{~mL}$ portion of the test suspension of L. pneumophila was filled into the titania-coated or Ag-doped titania-coated glass tube and circulated at a flow rate of $200 \mathrm{~mL} / \mathrm{min}$. Black-light lamps (BL, $6 \mathrm{~W} \times 4$, wavelength: $300-400 \mathrm{~nm}$, UV intensity: $5.0 \mathrm{~mW} / \mathrm{cm}^{2}$ ) or germicidal lights (GL, $6 \mathrm{~W} \times 4$, wavelength: $254 \mathrm{~nm}$, UV intensity: $7.0 \mathrm{~mW} / \mathrm{cm}^{2}$ ) located outside the glass tube were switched on to illuminate UV light. Small aliquots were then withdrawn from the suspension at intervals and examined for the presence of viable bacteria. The sampled suspensions were cultured on BCYE agar plates at $310 \mathrm{~K}$ for seven to ten days to determine the viable cell count $(N)$. The survival rate at each sampling time was defined as the ratio of $N$ to the initial viable cell count $\left(N_{0}\right)$ and is reported as a percentage. The experiments were repeated three times with different cultures of $L$. pneumophila, and reproducibility in data was observed.

The photocatalytic disinfection of L. pneumophila in Ag-doped titania-coated reactor was performed under the irradiation with the germicidal light for 24 hours. The test solution of $2 \mathrm{~mL}$, was sampled at time intervals $(0$, $0.25,0.5,1,4,8,12$, and 24 hours), and endotoxin concentration was measured by Limulus Amoebocyte Lysate assay (lower limit of detection: $1.0 \mathrm{pg} / \mathrm{mL}$ ).

A scanning electron microscope (JSM-6060; JEOL Ltd., Tokyo) was used to observe the shapes of the $L$. pneumophila before and after photocatalytic treatment for 12 hours. The samples for SEM observation were prepared as in our previous study (Hayakawa et al., 2007). 


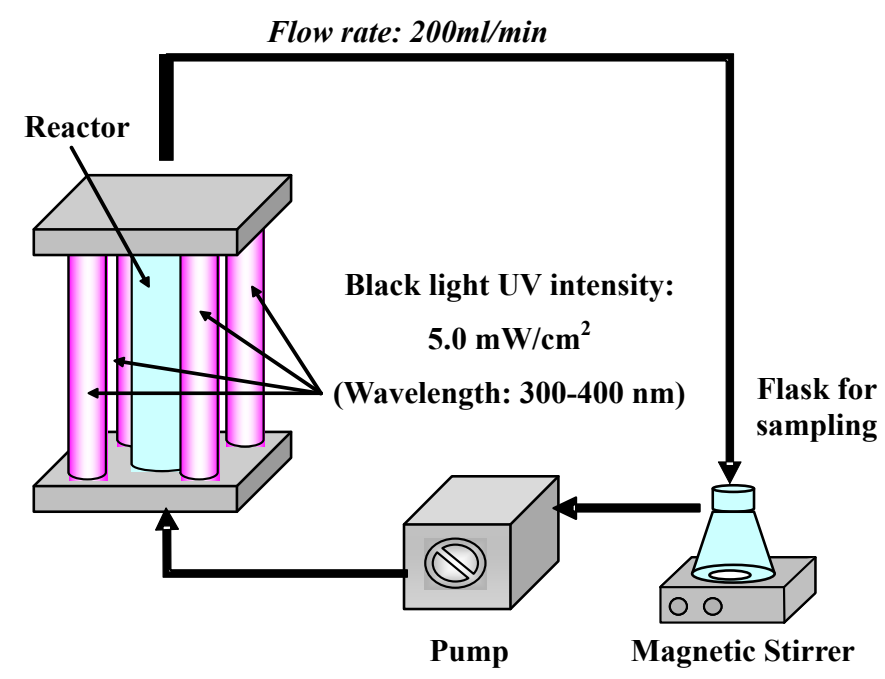

Figure 1. Schematic of the experimental apparatus

\section{Results and Discussion}

\subsection{XRD Analysis of Titania Thin Films}

Figure 2 shows the XRD patterns of titania thin films calcined at 473-773 K. Since anatase (101) peak $(2 \theta=$ $25.3^{\circ}$ ) in the titania thin film calcinated at $473 \mathrm{~K}$ is identified, it is found that crystallization to anatase started at low temperature. Other XRD patterns of titania thin films were clarified to be anatase phase of peaks relating to (101), (004), (200), (105), and (211) at 25.3, 37.8, 48.1, 53.9 and 55.1 ${ }^{\circ}$, respectively (Kiyono, 1991). Unfortunately, however, no peak of Ag was observed in the Ag-doped titania thin films. It is supposed because of the quantity of the doped silver, it is only $3 \mathrm{wt} \%$ to titania. Other features of titania thin films, for example, UV-vis spectra and SEM image, were reported in previous papers (Matsuo et al., 1990; Obuchi et al., 1995; Obuchi et al., 1999).

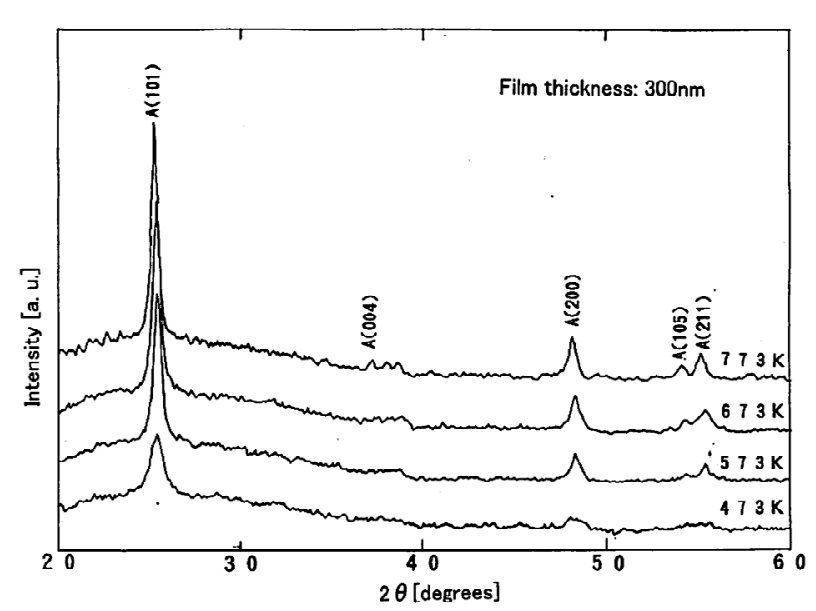

Figure 2. XRD patterns of titania thin films on the glass plate calcined at $473-773 \mathrm{~K}$

\subsection{Photocatalytic Disinfection in Titania-Coated and Ag-Doped Titania-Coated Reactors}

Figure 3 shows a plot of the survival rate of L. pneumophila against the process time for reactors coated with the thin film of titania (P-Ti) or Ag-doped titania (Ag-Ti) under black-light UV irradiation. The results follow a first-order rate law, and the estimated rate constants $\left(\mathrm{min}^{-1}\right)$ are shown in the figure. In the absence of a photocatalyst and with no UV irradiation (control), there was no disinfection of L. pneumophila. On the other hand, under UV irradiation, the survival rate of L. pneumophila decreased gradually in the absence of a 
photocatalyst. In the presence of a thin film of titania or Ag-doped titania under UV irradiation, the survival rate of L. pneumophila decreased rapidly, showing that the thin films of titania and Ag-doped titania that we prepared have photocatalytic activities. Surprisingly, however, the Ag-doped titania film also showed a slight disinfection of L. pneumophila in the absence of UV irradiation. Although it has been claimed that silver has a general bactericidal effect, the mechanism by which this effect is produced is unclear. However, our results suggest the possibility that the presence of $\mathrm{Ag}$ as a dopant might serve to overcome one of the weaknesses of photocatalytic disinfection, its inability to operate in darkness.

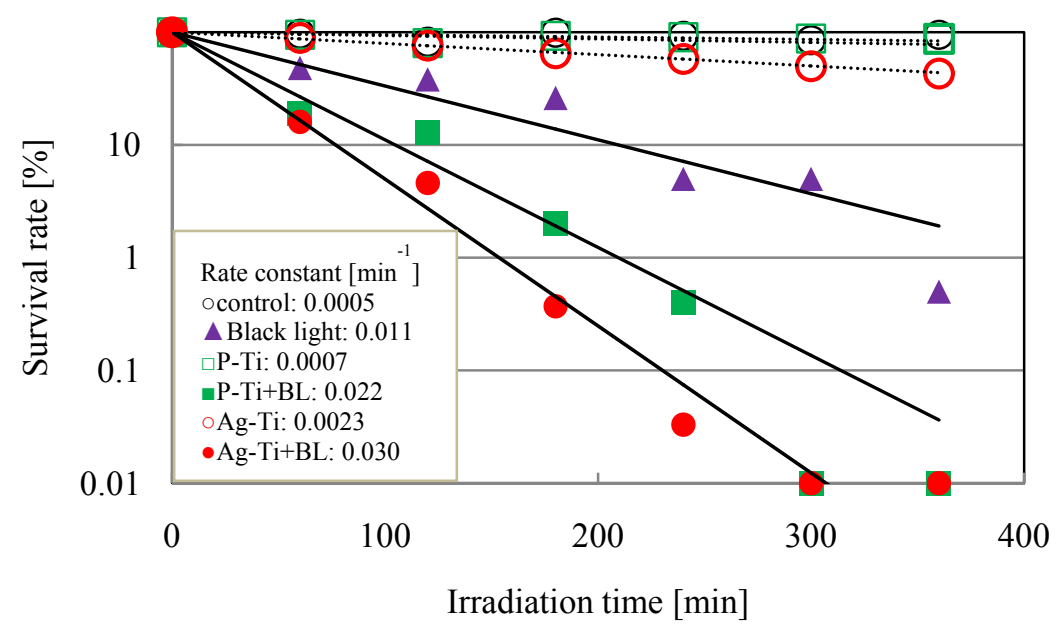

Figure 3. Plot of the survival rate of L. pneumophila against the process time. BL: black light; P-Ti titania thin film; Ag-Ti: silver-doped titania thin film

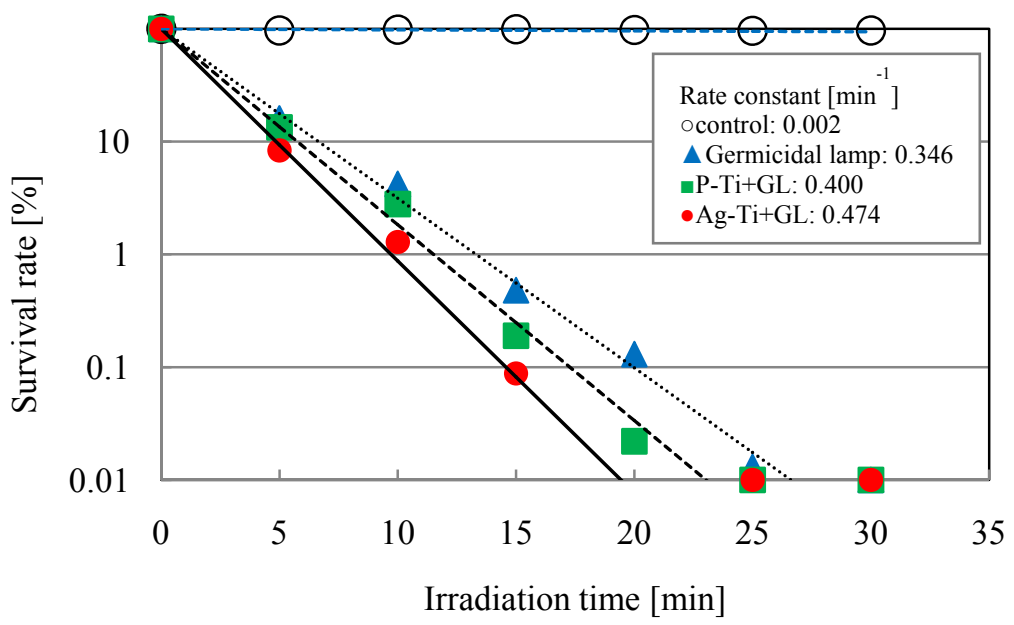

Figure 4. Plot of the survival rate of L. pneumophila against the process time for Ag-Ti and P-Ti thin film with irradiation by the germicidal light. GL: germicidal light; P-Ti titania thin film;

Ag-Ti: silver-doped titania thin film 


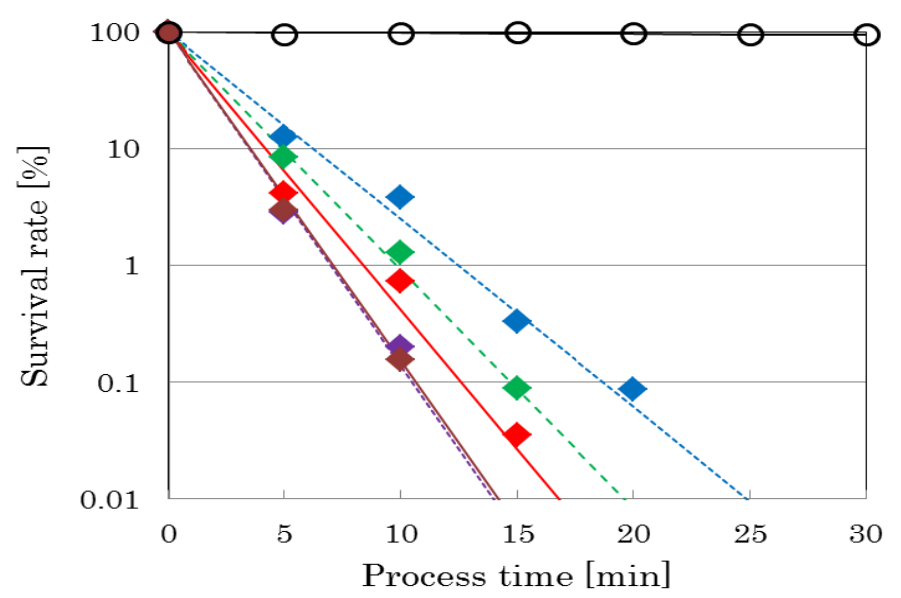

Figure 5. Plot of the survival rate of L. pneumophila against the process time at various flow rates in the presence of thin films of silver-doped titania films and GL irradiation

$$
\text { O: Control; } \diamond: \mathrm{Ag}-\mathrm{Ti}+\mathrm{GL}(\diamond: 100 ; \diamond: 200 ; \diamond: 600 ; \diamond: 800 ; \diamond: 1000 \mathrm{~mL} / \mathrm{min})
$$

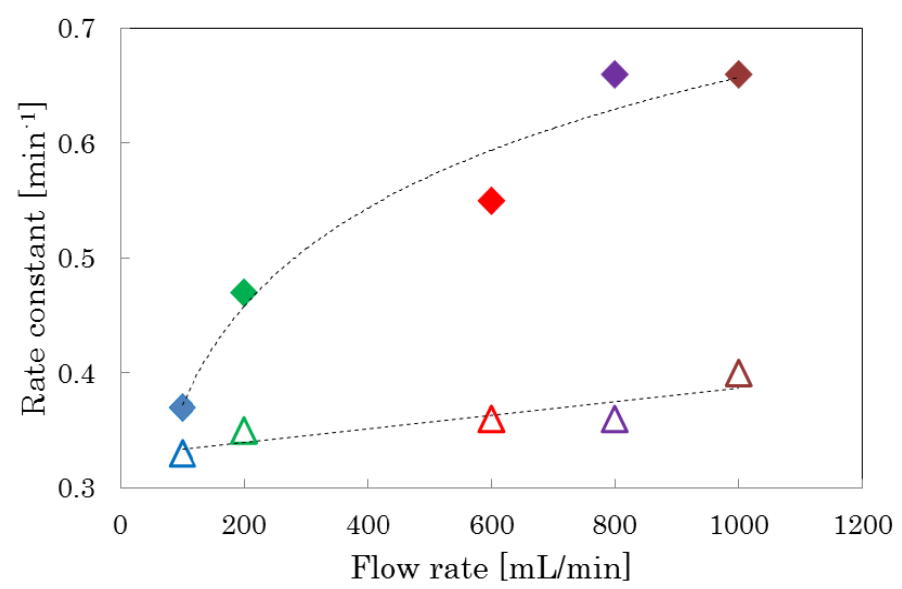

Figure 6. Dependence of the reaction rate constant on the flow rate

$$
\triangle: \mathrm{GL}(\triangle: 100 ; \Delta: 200 ; \Delta: 600 ; \Delta: 800 ; \Delta: 1000 \mathrm{~mL} / \mathrm{min})
$$

$\diamond: \operatorname{Ag}-\mathrm{Ti}+\mathrm{GL}(\diamond: 100 ; \diamond: 200 ; \diamond: 600 ; \diamond: 800 ; \diamond: 1000 \mathrm{~mL} / \mathrm{min})$

As shown in Figure 4, when the germicidal light (GL) was used as a source of UV radiation instead of the black light (BL), the survival rate of $L$. pneumophila decreased markedly regardless of the presence or absence of the photocatalyst. Because the germicidal light produces sterilizing rays at around $254 \mathrm{~nm}$, it disinfects $L$. pneumophila by its own action rather than through activation of a photocatalyst. When thin films of titania or Ag-doped titania were used under GL irradiation, the disinfection rates were 15-18 times higher than those under BL irradiation. In our previous paper (Hayakawa et al., 2007), we reported L. pneumophila could be disinfected photocatalytically using titania thin film on a glass plate irradiated with UV. Yao, Ochiai, Ishiguro, Nakano and Kubota (2011) reported photocatalytic disinfection of L. pneumophila using $\mathrm{TiO}_{2}$-coated ceramic foam and $\mathrm{Cu}^{2+} / \mathrm{TiO}_{2}$-coated ceramic foam in batch reactor (Ishiguro et al., 2013). In this work, it was found that $L$. pneumophila could be disinfected while circulating the test solution using the reactor coated with titania or Ag-doped titania thin films, and the germicidal light (wavelength: $254 \mathrm{~nm}$ ) is more effective compared with BL for practical processing, where continuous sterilization system is utilized.

Figure 5 shows the changes in the survival rates of L. pneumophila when the flow rate of the test suspension was increased in stages from $100 \mathrm{ml} / \mathrm{min}$ to $1000 \mathrm{ml} / \mathrm{min}$ under GL irradiation in the presence of Ag-doped titania. The rate constants for L. pneumophila disinfection increased almost proportionately with increasing flow rate 
(Figure 6). In the case of a low flow rate, a thick boundary layer is present between the surface of the photocatalytic thin film and the test suspension containing $L$. pneumophila, whereas at higher flow rates, this boundary layer becomes thinner. The rate of mass transfer of $L$. pneumophila to active sites on the surface of the photocatalyst is dependent on the thickness of the boundary layer. Therefore, in the case of a high flow rate, $L$. pneumophila can move easily to the active sites, and the rate constant for $L$. pneumophila disinfection increases. When GL irradiation was used alone without a photocatalyst, the flow rate of the test suspension had barely any effect.

\subsection{Scanning Electron Microscopy Observations of L. pneumophila}
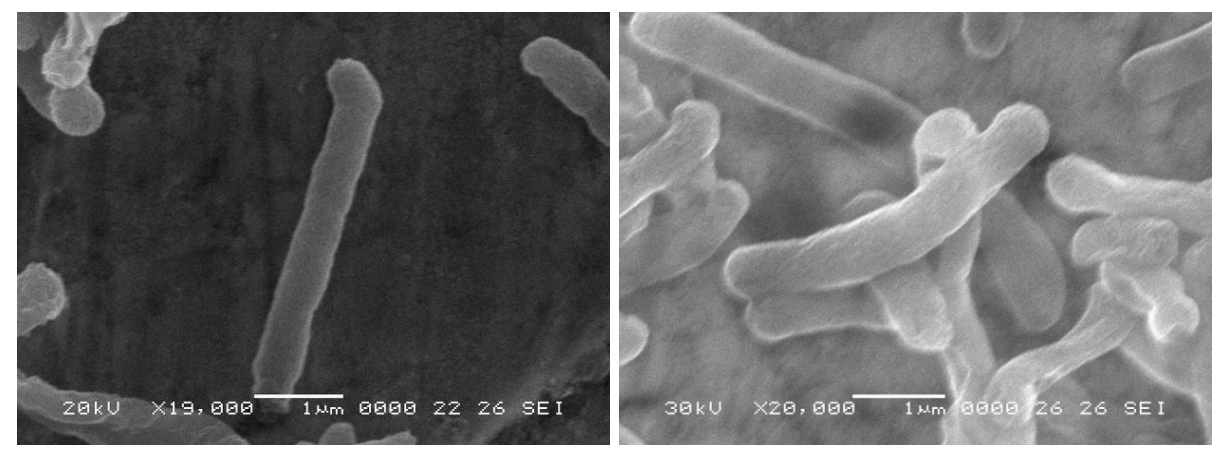

Figure 7(a). Scanning electron micrographs of L. pneumophila (Control)
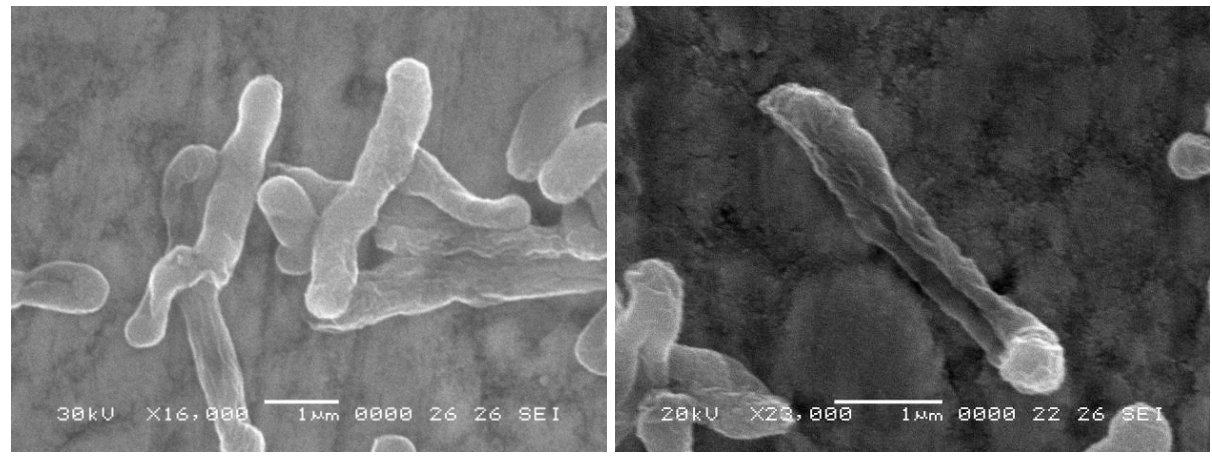

Figure 7(b). Scanning electron micrographs of L. pneumophila irradiated with the GL
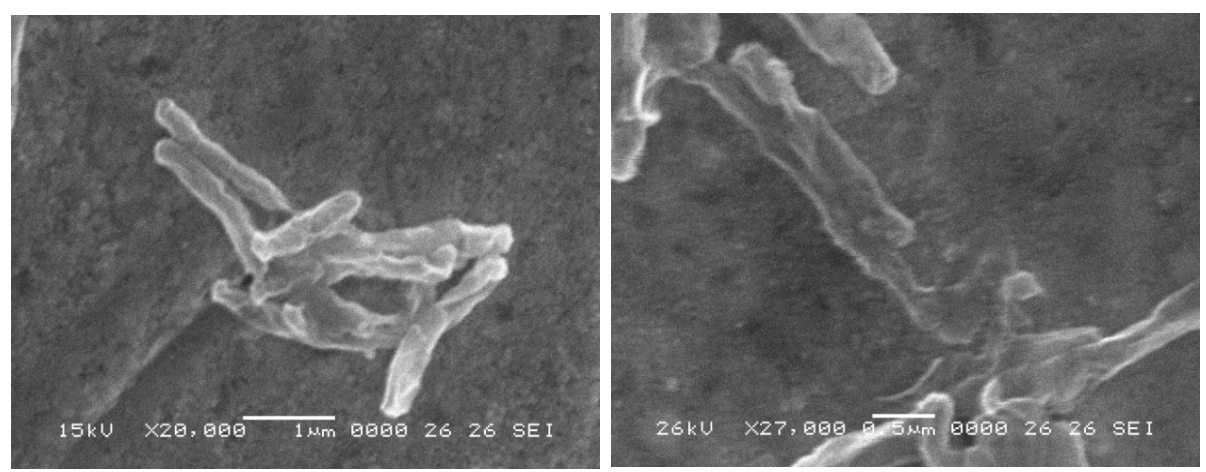

Figure 7(c). Scanning electron micrographs of L. pneumophila irradiated with the GL in the presence of a thin film of titania (P-Ti) 

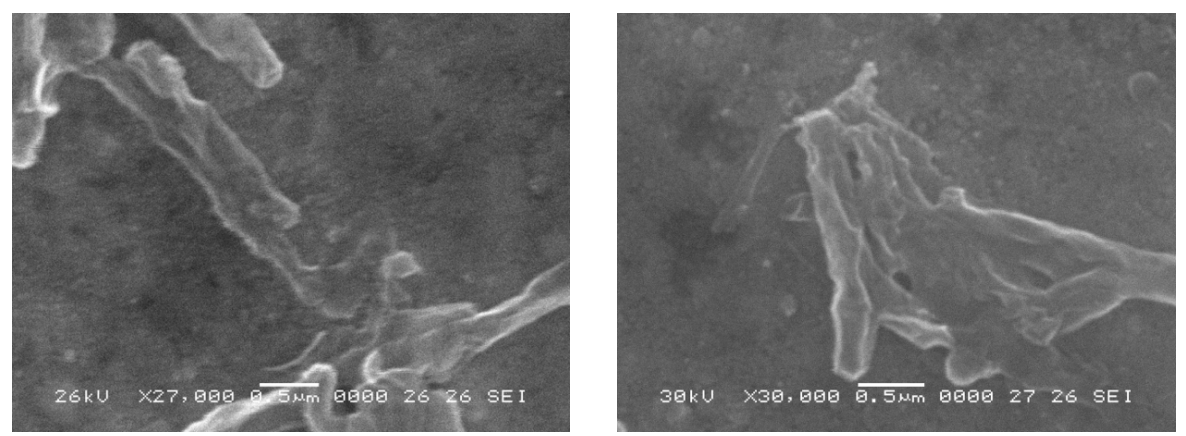

Figure 7(d). Scanning electron micrographs of L. pneumophila irradiated with the GL in the presence of a thin film of silver-doped titania (Ag-Ti)

Scanning electron micrographs of L. pneumophila after various treatments for 12 hours are shown in Figures 7(a) - 7(d). Figure 7(a) is of the control. Figure 7(b) shows the bacteria after GL irradiation in the absence of a photocatalyst. Figures 7(c) and 7(d) show bacteria subjected to GL irradiation in the presence of thin films of titania (P-Ti) or Ag-doped titania (Ag-Ti), respectively. When the germicidal light was used as the radiation source, the survival rate constant of L. pneumophila was similar in the presence or absence of photocatalyst, as discussed in Section 3.2. However, in the scanning electron micrographs, the shapes of the L. pneumophila treated in the presence of the two films show obvious differences from those treated by irradiation alone. The appearance of $L$. pneumophila subjected to GL irradiation in the absence of a photocatalyst was relatively unchanged, although wrinkles developed on the surfaces of the bacteria. On the other hand, the cell walls of $L$. pneumophila were destroyed in the presence of the thin-film Ag-titania photocatalyst. This clearly shows that the photocatalyst has an additional effect to GL irradiation alone.

Endotoxin, a component of the outer membrane of Gram-negative bacteria, leaks from dead bacteria and is highly toxic, even at very low concentrations. When the outer membrane of the L. pneumophila was destroyed, as observed in Figure 7, a leakage of endotoxin was detected. However, the endotoxin was photocatalytically decomposed after 12 hours of treatment, as shown in Figure 8. Sunada, Kikuchi, Hashimoto, and Fujishima (1998) already reported endotoxin from $E$. coli could be decomposed using $\mathrm{TiO}_{2}$ photocatalyst. In our work, it was shown clearly that endotoxin could be decomposed below the detection limit within 24 hours, despite high concentration of endotoxin $(2,000 \mathrm{pg} / \mathrm{mL})$ leaked from dead L. pneumophila. For removal or inactivation of endotoxin leaked from dead bacteria, the filtration using reverse osmosis and inactivation using some chemicals have been known currently in practical processes. The result from our experiments could show that endotoxin was decomposed simultaneously during the sterilization of $L$. pneumophila, without the chemical or the physical processing mentioned above.

Considering the practical utilization of photocatalyst, the durability of a thin film is very important. It had already reported that a titania thin film had tolerance to acid or alkali (Obuchi et al., 1999). In this paper, it was examined whether it could be used repeatedly and be kept photocatalytic activity of Ag-doped titania thin film for long time. Figure 9 shows the plots of the survival rate of $L$. pneumophila vs. total irradiated time. At first, photocatalytic sterilization of L. pneumophila was performed during 30 minutes under GL irradiation, and stopped the operation for cleaning up. In the clean-up operation, the reactor tube was heated at $60{ }^{\circ} \mathrm{C}$ and $2 \mathrm{~atm}$ in the autoclave for 15 minutes. After the clean-up operation, the fresh test solution including L. pneumophila (the concentration was approximately $6 \times 10^{5} \mathrm{cfu} / \mathrm{mL}$ ) was added. This sterilization and cleaning cycle was repeated 10 times. No viable $L$. pneumophila was detected after 25 minutes for each cycle, so that a thin film of Ag-doped titania was found to retain the photocatalytic activity. 


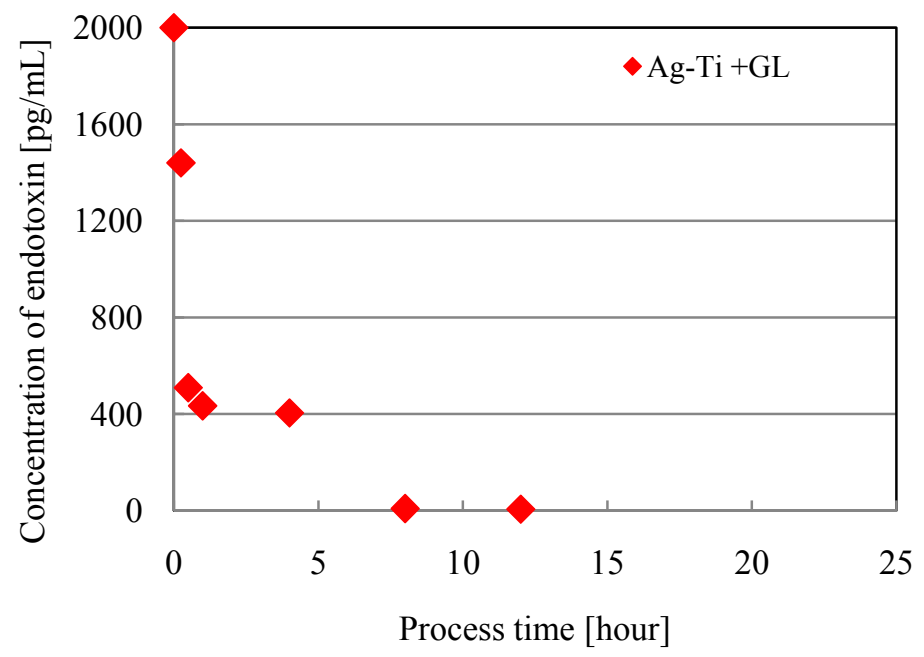

Figure 8. Plot of the concentration of endotoxin of L. pneumophila against the process time using Ag-Ti thin film with irradiation by the germicidal light

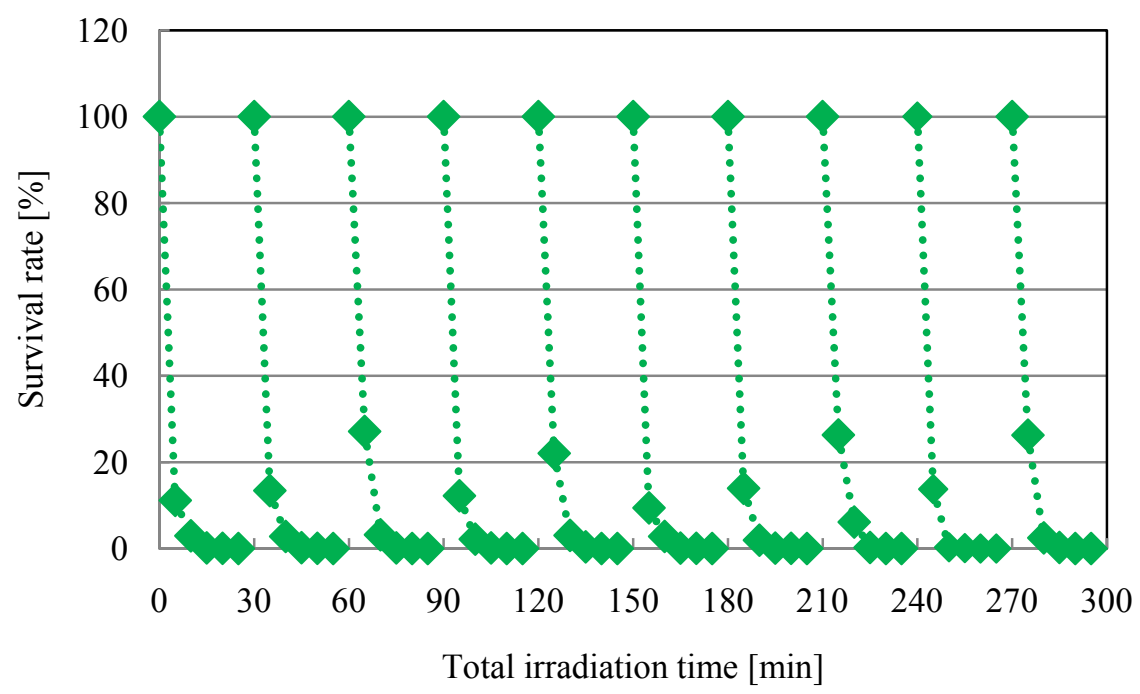

Figure 9. Continual sterilization operations using a Ag-Ti coated quartz glass tube with irradiation by the germicidal lights. Every 30 minutes, fresh test solution including L. pneumophila was added in the reactor

\section{Conclusions}

We conclude that thin films of titania or Ag-doped titania can disinfect L. pneumophila effectively when subjected to UV irradiation. Endotoxin leaking from the dead $L$. pneumophila can be decomposed simultaneously within 24 hours. Ag-doped titania shows a slight disinfecting effect on L. pneumophila in even in the absence of UV irradiation.

The titania and Ag-doped titania solutions prepared in this work can be readily coated onto glass, heat-resistant steel, or other materials; that might be useful in designing and developing an attractive new type of practical reactor for disinfecting various kinds of bacteria, such as Staphylococcus aureus, MRSA, E. coli, and Bacillus subtilis, in aqueous media (Obuchi, Fujikawa, Katoh, Kuroiwa, \& Nakano, 2011).

\section{References}

Augugliaro, V., Palmisano, L., Schiavello, M., Sclafani, A., Marchese, L., Martra, G., \& Miano, F. (1991). Photocatalytic degradation of nitrophenols in aqueous titanium dioxide dispersion. Appl. Catal., 69, 323-340. http://dx.doi.org/10.1016/S0166-9834(00)83310-2

Chand, R., Obuchi, E., Katoh, K., Luitel, H. N., \& Nakano, K. (2011). Enhanced photocatalytic activity of 
$\mathrm{TiO}_{2} / \mathrm{SiO}_{2}$ by the influence of $\mathrm{Cu}$-doping under reducing calcination atmosphere. Catalysis Communications, 13, 49-53. http://dx.doi.org/10.1016/j.catcom.2011.04.024

Chen, Y., \& Dionysiou, D. D. (2006). $\mathrm{TiO}_{2}$ photocatalytic films on stainless steel: The role of Degussa P-25 in modified sol-gel methods. Appl. Catal. B, 62, 255-264. http://dx.doi.org/10.1016/j.apcatb.2005.07.017

Hayakawa, T., Kuroiwa, A., Higashi, E., \& Nakano, K., (2007). Photoinduced bactericidal effect of titania thin film against Legionella pneumophila. Med. Bull. Fukuoka Univ., 34, 71-81.

Hoffmann, M. R., Martin, S. T., Choi, W., \& Bahnemann, D. W. (1995). Environmental applications of semiconductor photocatalysis. Chem. Rev., 95, 69-96

Ishiguro, H., Yao, Y., Nakano, R., Hara, M., Sunada, K., Hashimoto, K., Kajioka, J., \& Fujishima, A. (2013). Y. Kubota, Photocatalytic activity of $\mathrm{Cu}^{2+} / \mathrm{TiO}_{2}$-coated cordierite foam incaticates bacteriophages and Legionella pneumophila. Applied Catalysis B, Environmental 129, 56-61. http://dx.doi.org/10.1016/j.apcatb.2012.09.012

Kakita, Y., Obuchi, E., Nakano, K., Murata, K., Kuroiwa, A., Miake, F., \& Watanabe, K. (2000). Photocatalytic inactivation of Lactobacillus PL-1 phages by a thin film of titania. Biocontrol Science, 5, 73-79.

Kiyono, M. (1991). Sanka Titan (in Japanese). Gihodo, Japan. ISBN 4-7655-0375-5.

Liu, L., Liu, Z., Bai, H., \& Sun, D. D. (2012). Concurrent filtration and solar photocatalytic disinfection/ degradation using high-performance $\mathrm{Ag} / \mathrm{TiO}_{2}$ nanofiber membrane. Water Research, 46, 1101-1112. http://dx.doi.org/10.1016/j.watres.2011.12.009

Liu, R., Wang, P., Wang, X. Yu, H., \& Yu, J. (2012). UV- and visible-light photocatalytic activity of simultaneously deposited and doped $\mathrm{Ag} / \mathrm{Ag}(\mathrm{I})-\mathrm{TiO}_{2}$ photocatalyst. Journal of Physical Chemistry C, 116, 17721-17728.

Matsuo, K., Takeshita, T., \& Nakano, N. (1990). Formation of thin films by the treatment of amorphous titania with $\mathrm{H}_{2} \mathrm{O}_{2}$. J. Crystal Growth, 99, 621-624.

Nakano, R., Chand, R., Obuchi, E., Katoh, K., \& Nakano, N. (2011). Performance of $\mathrm{TiO}_{2}$ photocatalyst supported on silica beads for purification of wastewater after absorption of reflow exhaust gas. Chemical Engineering Journal, 176-177, 260-264. http://dx.doi.org/10.1016/j.cej.2011.05.072

Obuchi, E., Yamamoto, K., \& Nakano, K. (1995). Preparation of transparent titania thin film as a catalyst. Kagaku Kogaku Ronbunshu, 21, 1075-1081.

Obuchi, E. Hashimura, M., \& Nakano, K. (1999). Control of film thickness in the preparation of titania thin films. Kagaku KogakuRonbunshu, 25, 849-853.

Obuchi, E., Fujikawa, M., Katoh, K., Kuroiwa, A., \& Nakano, K. (2011). Study on photocatalytic sterilization of Bacillus subtilis using Ag-doped $\mathrm{TiO}_{2} / \mathrm{SiO}_{2}$. The $9^{\text {th }}$ International meeting of Pacific Rim Ceramic Societies.

Reddy, M. P., Venugopal, A., \& Subramanyam, M. (2007). Hydroxyapatite-supported $\mathrm{Ag}-\mathrm{TiO}_{2}$ as Escherichia coli disinfection photocatalyst. Water Research, 41, 379-386. http://dx.doi.org/10.1016/j.watres.2006.09.018

Rengifo-Herrera, J. A., Mielczarski, E., Mielczarski, J., Castillo, N. C., Kiwi, J. \& Pulgarin, C. (2008). Escherichia coli inactivation by $\mathrm{N}, \mathrm{S}$ co-doped commercial TiO2 powders under $\mathrm{UV}$ and visible light. Appl. Catal. B, 84, 448-456. http://dx.doi.org/10.1016/j.apcatb.2008.05.013

Rincón, A. G., \& Pulbarin, C. (2003). Photocatalytical inactivation of E. coli: effect of (continuous - intermittent) light intensity and of (suspended - fixed) $\mathrm{TiO}_{2}$ concentration. Appl. Catal. B, 44, 263-284. http://dx.doi.org/10.1016/S0926-3373(03)00076-6

Shiraishi, F., Toyoda, K., Fukinbara, S., Obuchi, E., \& Nakano, K. (1999). Photolytic and photocatalytic treatment of an aqueous solution containing microbial cells and organic compounds in an annular-flow reactor. Chem. Eng. Sci.,54, 1547-1552.

Sunada, K., Kikuchi, Y., Hashimoto, K., \& Fujishima, A. (1998). Bactericidal and detoxification effect of $\mathrm{TiO}_{2}$ thin film photocatalysts. Environmental Science \& Technology, 32(5), 726-728.

Ubonchonlalate, K., Sikong, L., \& Saito, F. (2012). Photocatalytic disinfection of P. aeruginosa bacterial Ag-doped $\mathrm{TiO}_{2}$ film. Procedia Engineering, 32, 656-662. http://dx.doi.org/10.1016/j.proeng.2012.01.1323

Yao, Y., Ochiai, T., Ishiguro, H., Nakano, R., \& Kubota, Y. (2011). Antibacterial performance of a novel photocatalytic-coated cordierite foam for use in air cleaners. Applied Catalysis B, Environmental 106, 592-599. http://dx.doi.org/10.1016/j.apcatb.2011.06.020 


\section{Copyrights}

Copyright for this article is retained by the author(s), with first publication rights granted to the journal.

This is an open-access article distributed under the terms and conditions of the Creative Commons Attribution license (http://creativecommons.org/licenses/by/3.0/). 